International Journal of Linguistics, Literature and Culture
Available online at https://sloap.org/journals/index.php/ijllc/
Vol. 7, No. 4, July 2021, pages: 255-262
ISSN: 2455-8028
https://doi.org/10.21744/ijllc.v7n4.1785

\title{
Mother Tongue Disability and Socio-Cultural Development in Nigeria
}

Esiri May Omogho ${ }^{\text {a }}$

Article history:

Submitted: 9 March 2021

Revised: 18 April 2021

Accepted: 14 May 2021

\section{Keywords:}

development

disability

language

mother tongue

Nigeria

socio-cultural

\begin{abstract}
Mother tongue disability refers to some or total inadequacy in one's native language. It implies a situation where individuals or groups of persons are unable to speak/ write their native language. This is a common phenomenon among Nigerian youths. As a result, research has shown there are over 450 indigenous languages in Nigeria, which may go extinct (Rotimi, 2012; Bankole, 2010). Colonization and the introduction of western civilization had often been blamed for mother-tongue disability. However recent happenings indicate that factors such as the fast decreasing value for mother tongue and parental negative attitudes may be more responsible for mother-tongue disability. The paper aims at explaining the causes and effects of mother tongue disability in Nigeria and its consequences on socio-cultural development in the country. It concludes that speaking, writing, as well as the understanding of mother tongue, is beneficial for social solidarity, peaceful co-existence (without which there cannot be meaningful development), the maintenance of cultural heritage and values, and for the growth of the tourism industry. Therefore, it strongly recommends that government should urgently do more to revive and emphasize native languages through schools and media organizations and if possible should make the ability to speak native tongue criteria for employment.
\end{abstract}

International journal of linguistics, literature and culture (C) 2021. This is an open access article under the CC BY-NC-ND license (https://creativecommons.org/licenses/by-nc-nd/4.0/).

Corresponding author:

Omogho, E.M.

Department of Sociology and Psychology, Delta State University, Abraka

Email address: mayesiri@gmail.com

${ }^{a}$ Foreign Languages \& Applied Linguistics, Shanghai International Studies University (SISU), China 


\section{Introduction}

Language is simply the expression of self and the ability to share that expression with others. The learning of mother tongue will enable an individual study their culture and it will preserve family bond and lessen cultural conflicts between generations. Mother tongue has been defined by various social scientists and linguists in many ways. Adams \& Tulasiewics (2005), define mother tongue as a language that a person learns from the mother and close family members through interaction with them as well as through interaction with the environment, and which commands a place in one's sub consciousness, thus strongly linking the individual with the society. Adekunle (1960) distinguishes mother tongue from 'cradle tongue'. Like Bankole (2010), he explains mother tongue as being the language one happens to learn during early childhood. While one's own native language may be different, possibly determined by an intended linguistic race and may later in life be discovered by a strong emotional affinity to a specific dialect. Tolkien in Hammond \& Scull (2017), also claims that mother tongue is the language one learns during early childhood. This view is similar to Kochanska \& Aksan's, view (Kochanska \& Aksan, 1995) but it is not the 'mother tongue' this study is concerned with.

Cleo (2001), on his part notes that the term 'mother tongue' has generally been given various interpretations that are biased linguistically, especially with respect to bilingual children form ethnic minority groups. He cites his own experience as a bi-lingual student of Portuguese and Riograndender Hunsinekisch, a German rooted language brought to Southern Brazil by the first German immigrants. In this case, like that of many children whose home language differs from the language of the environment (the official language), it is debatable which language is one's mother tongue. Also, Adams \& Tulasiewics (2005), observes that mother tongue refers to a person's community language that is spoken in a particular time, that helps him/her grow into a certain linguistic view and understanding of the world in its history and production. Again, Ferguson (1968) defines mother tongue as the language the child first learned at home in childhood and which is still understood by the individual in the process of time: in adulthood. This is because it is quite possible that the first language learned is no longer a speaker's dominant language at a later date. This includes young immigrant children whose families have moved to a new linguistic environment as well as people who learned their mother tongue as young children at home (rather than the languages of the majority), who may have lost in part or in totality, the language they first acquired (language affinity).

According to Wikipedia, the free encyclopedia (2008), a mother tongue also called a native language or arterial language, is the language that a person has learned from birth or within the crucial period of growth, or that a person speaks best and so it is often the basis of socio-linguistic identity. In some countries, the term 'native language' or 'mother tongue' refer to the language of one's ethnic group rather than one's first language. Sometimes, there can be more than one mother tongue when the child's parents speak different languages. These children are usually called bi-lingual (Wikipedia, the free encyclopedia, 2008). This second part of the definition is fitting for this work. In this work mother tongue refers to the language of one's ethnic group and not necessarily the language prevalent in the environment. When children's parents are from different ethnic groups, they have two mother tongues according to the definition. This definition of 'mother tongue' or 'mother language' is different from the United Nations definition, which says that mother tongue is the language usually spoken in the individual's home in his or her early childhood (Warren, 1994).

Mother tongue disability amongst Nigerian youths is a problem that requires urgent attention because it can lead to the loss of an individual's cultural identity (Adekunle, 1960; Paker \& Karaağaç, 2015). This is possible in a situation where an Urhobo individual is unable to speak or/and understand his mother tongue but can speak or barely understand the Urhobo languages but writes, speaks and understands another native language (for example Yoruba language) very fluently, people will begin to associate him with the Yoruba people instead of the Urhobo people.

In recent times, youths have been seen to boast about and compete in their ability to speak, write and understand the English Language, when same cannot be said regarding their mother tongue. Thus, though many of the youths understand their native language; and when some are questioned as to their inability to speak, understand or write in their mother tongue, they ask if it is going to put food on the table for them (Adekunle, 1960). Again, others feel shame and disdain for their mother tongue, associating it with locality, backwardness and uncivilisation. Some even ridicule those who speak their native language as being uncivilized (Okafo, 2011; Ezenwa-ohaeto \& Akujobi, 2013). They appear to be happily basking in a false image that presents a scenario that their inability to speak or understand their language makes them appear posh and as a result, they now replace their native names with English names or make them look or sound like European names (Okafo, 2011; Love \& Ansaldo, 2010). For example, the name 'Ochuko' becomes 'Ochukes' or 'chuks and Rukwevwe' becomes 'Ruky'or' Rukies' and many others (Okafor, 2011; Murphy \& de Larios, 2010). 
Inability to speak or understand one's language, weakens the ties between such a person and his kinsmen. This is because language brings people together and enables them understand each other. Without language the opposite (chaos) is the case. When an individual is able to understand or speak his mother tongue, his kinsmen will identify with him. One of the primary agents of child socialization are the parents (Giddens, 2009). Their duties include to speak mother tongue to their children and ensure that they do not only learn and understand their native tongues but also if possible, write in them. However, contrary to this expectation, parents are seen in recent times to contribute to mother tongue disability: they are more particular about raising children that are more versed in foreign languages, especially English language (Okafo, 2011; Seid, 2016). This is almost becoming a norm such that some parents proudly tell others that their children are unable to speak or understand their mother tongue. Thus, some parents would rather speak English language or pidgin (Nigerian pidgin) instead of their mother tongue when communicating with their children.

Also, government and policy makers, who ought to make laws to promote mother tongues, do so in favour of foreign languages such as French, English, Spanish and others, and this is detrimental to the country's cultural heritage. Since language is simply the expression of self and the ability to share that expression with others (Cummins, 2001), it therefore follows that learning and speaking of mother tongue will enable an individual study their culture and it will preserve family bonds and lessen cultural conflicts between generations. It has been observed that some children may speak certain languages but may not know their mother tongue or even the sound of their mother tongue. Therefore linguistics and communication experts, posit that some languages could go into extinction in the next hundred one hundred years (Malv, 2004; Hicks et al., 2015). In Nigeria, research reveals that over 450 indigenous languages may eventually become extinct in the next century if Nigerians continue to place little value on mother tongue (Rotimi, 2012; Bankole, 2010).

\section{The Effects of Mother Tongue Disability on Socio-Cultural Development}

Akindele \& Adegbite (1999), observed in reference to the colonial period in Africa, that community attitudes were directed towards believing that everything European was excellent and should be imitated, whereas all which belonged to the local African community were seen to be inferior. This was due to the fact that the European language (English language) lifted the status of people because it was those who spoke the language that often had access to jobs. In line with this, Macaulay (2004) notes that in Nigeria, English is the language of power and is socially and economically beneficial to its users because the country is dominated economically and socio-politically by the elites. He also pointed out that language based problems are major causes of the spate of juvenile delinquency and Area Boys syndrome in Nigeria.

Mother tongue disability simply reflects the opposite of a situation where a native speaker speaks and understands his mother tongue (which is the language of his ethnic group). Therefore, mother tongue disability is a situation where an individual cannot speak or is unable to speak or understand his/her native language. Researches carried out by Moyo, (2001) and Nondo (1996) in Zimbabwe, revealed the negative attitudes by parents towards the African languages (mother tongue) that are passed on to sthe children. Parents of children at Wankie secondary school regarded Ndebele, their mother tongue as of no value to their children's lives since it did not render a person employable. Parent's felt that English was more important and relevant to the future of their children and as such, they hardly spoke the mother tongue (Moyo, 2001; Nondo, 1996). This implies mother tongue disability. As Setati (2005) \& Magwa (2015) observed, Africans still resist mother tongue education but prefer the English language which they view as the 'language of knowledge'.

Aboiralor (2008) writing on the decline of the mother tongue in Africa explains that one of the significant aspects of any culture is language. In his own words, "This is a combination of sounds and gestures which facilitate communication and tells who we are and where we are and where we come from. It is a very unique tool for identification" (Aboiralor, 2008). Language serves to identify an individual. Sometimes, one may correctly tell another's descent from his accent even when he is not speaking his mother tongue because of his phonetic sounds. This signifies the unique position of language in our culture. Hence, Aboiralor (2008) suggests that Nigerians must do everything possible to ensure that mother tongue is eternally preserved, for by so doing, they would be making their ancestors and history more relevant as offering their generation great service.

In many African homes, where both parents belong to different ethnic groups; the common language spoken is a foreign one. However, the expectation in such situations would have been that the children be taught to speak both languages which in turn would be an advantage. Observation has nevertheless revealed that oftentimes they never

Omogho, E. M. (2021). Mother tongue disability and socio-cultural development in Nigeria. International Journal of Linguistics, Literature and Culture, 7(4), 255-262. https://doi.org/10.21744/ijllc.v7n4.1785 
learn any (Aboiralor, 2008; Awopetu, 2016). This situation becomes more grievious as such children grow into adults because the language of schooling is foreign (often times English; if not always) and if eventually they get married to persons who like them cannot speak their mother tongues, a more complex situation then develops. There is no doubt that mother tongues disability can result in the problem of loss of identity, social and economic alienation and extinction of some languages if allowed to continue. Hence he concludes that, mother-tongue disability may sooner or later in the future result in the extinction of some African native tongues.

Most importantly, inability to use mother tongue well causes communication problems in all domains of life. Ability to rightly convey feelings and ideas depemd on the right use of mother tongue. It makes language understandable by others, clearer and more useful which in turn facilitates a better operation of our comprehension faculty. A complicated and underdeveloped language itself hinders thinking and imprisons comprehension (Ferguson, 1968; Fishman, Ferguson \& Gupata 1968). When we fail to preserve our mother tongue, we will live a spiritless life with no true bonding because we do not appreciate and respect our language (Aboiralor, 2008). As a result, it will be impossible to forge mutual respect and cohesion among ourselves (Aboiralor, 2008).

\section{Causes of Mother Tongue Disability}

Studies have identified causes of mother tongue disability to include its non-inclusion in academic usage, visual impairment, parent's attitudes, perceived importance of a national or second language and socio-economic background (Rotimi, 2012; Abioralor, 2008; Roy, 1996). According to Roy (1996), when mother tongue is not used for educational purposes, children may not see or attach any importance to it. They will prefer to concentrate on the language for instruction in their schools. As children realize that their mother tongue will not be useful to them in their classroom or for passing their exams, they become less interested in speaking or learning their mother tongue.

Lack of vision, inability to determine if ones conversation partner is attending to them, and the interest level of a person to whom one is talking may also affect the social use of a language. Vision seems to allow children generalize and broaden semantic association. However, visual impairment may slow down the process of learning native tongue but does not prevent anyone from learning his or her language. Dingari (2009), stressed the extent of parent's negative attitudes towards their mother tongue when she contrasted parents of past generations with today's parents. According to her, the first immigrant parents were able to teach children their language, tradition, religion and classical dance; and children were able to participate in their cultural functions, and they felt very proud. However, she observed that he second and third generation parents were so busy with their jobs that they did not mind if their children showed interest in learning mother tongue or not. They forget that mother tongue shapes the identity of the child and enhances national consciousness and development. Babajide (2001) \& Rotimi (2012) pointed out on their part that inability by individuals to perceive the socio-economic and political relevance of a language in their lives, makes them limit the use of the language.

For example, in Nigeria where the national language is English, for any individual to be politically and/or socioeconomically relevant, he/she must acquire some knowledge of English. In line with this, (Rotimi, 2012) notes that when children and young persons are exposed to foreign music and other international events, which are mainly nonindigenous cultures, their scope and power of English languageas as well as foreign cultures are increased to the detriment of the indigenous ones. Similarly, with very little meaningful roles for the mother tongues in contemporary everyday life, particularly in commerce, education, writing, the acts and the media, the younger generation does not see the usefulness of their mother-tongue except for occasional use with family and friends. As a result, they neglect their mother-tongue. Again, Babajide (2001) observes that socio-economic status is a factor that affects activities towards languages. According to him, Nigerian children including some adults from the upper social-economic background are English monolinguals and monoculturals.

\section{Theory}

The paper applies the functionalist theory as developed by Emile Durkheim (1858-1917) and Talcott Parsons (19021978). The Functionalist theory explains how social systems are maintained and positively evaluates the workings of the parts of the society. Thus functional theorists investigate how functional prerequisites are met, and concentrate on functions rather than dysfunctions. According to Durkheim (1938), the actions, thinking and feelings of members of society are constrained by social facts which are external to them. As a result, such social facts control the individuals in society by ways of acting, thinking and feeling, external to the individual and which controls him/her. 
Belief and moral codes are passed on from one generation to the next and shared to individuals who make up a society. From this point of view, it is not the consciousness of the individual that directs behaviour, but common beliefs and sentiments that transcend the individual and shape his or her consciousness.

Durkheim (1938) argued that there are two ways of explaining social facts. In both cases, the explanation lies in the society. The first method assumes that the cause of a social fact lies in its origin. Thus, the determining cause of a social act should be sought among the proceeding acts and not among the state of individual consciousness. However, the process of explaining a social fact must be concerned also with its function in society; and contribution to the general needs of society as well as social order. Durkheim concludes that social life is obtainable through the existence of a "collective conscience" which consists of common beliefs and sentiments, and without which social solidarity cannot be achieved. Also, without which individuals would not be bound together to form an integrated social unit and without social obligations backed by moral force, the cooperation and reciprocity that social life require would be absent. Instead, narrow self-interest rather than mutual obligations would be the guiding force, leading to disorderliness in society. The collective conscience constrains individuals to act in terms of the requirement of society. Since the collective conscience is a social fact and therefore external to the individual, it is essential that it be impressed upon him/her. Therefore, Durkheim argues that society has to be present in the individual.

The functionalist theory as discussed is applicable because mother tongue is a fact found in all societies of the world. It is an aspect of culture and it performs certain functions in a particular society. It is functional for both societies and individuals as it facilities communication among members of a society. It also provides unity and makes room for development. The ability of the youths (that is, the leaders of tomorrow) to speak their mother tongue and pass it from generation to generation, will ensure cultural preservation which in turn will boost the tourism industry in the developing nation of Nigeria. It also provides an individual with identity (i.e. culture identity) which enables him to act in the ways of his people due to the fact that his people have their ways or pattern of doing things or living their lives, different from others.

However, when one is unable to speak or understand his language, it is assumed that he does not know much about his people. Mother tongue disability will lead to communication breakdown and the absence of social solidarity between an individual and his kinsmen. He will therefore not be functional to his people since he will find it very difficult to perform or carry out his obligations as a member of a particular ethnic group. For instance, when an Isoko man who is unable to speak or understand the Isoko language visits his village or ethnic homeland, he will be unable to communicate with his people. When he hears others speaking his language to him, we will be 'lost'. However, when one speaks and understands the language of his people or members of his ethnic group, they will tend to associate with him since they will assume they share common beliefs and sentiments with him. In additional, he will be confident when he stands before his people and will then able to relate with them and perform his social obligations as a member of that particular ethnic group.

\section{Conclusion}

Mother tongue disability is prevalent among Nigerians and this is leading to a gradual loss of cultural identify, cultural values, national unity and lose in the tourism industry, as well as the possible extinction of mother tongue in the future. As rightly observed by Vice Web \& Kembo Sure (2000), language based problems exist in the area of education, the economy, politics and social life with apparent language components. This implies that, language is very significant to their existence, performance and growth in society. Mother tongue disability is majorly caused by the inability of parents to interact with their children using mother tongue and the importance attached to English language in the Nigerian society. Therefore, urgent steps need to be taken to address the problem of mother tongue disability in Nigeria.

\section{Recommendations}

The paper recommends from the discussions as follows:

- Those parents should consistently speak mother tongue to their children and also insist that their children speak the same in the home.

- Parents should make out time to visit their native lands/homelands as often as possible with their children, and if possible spend meaningful time interacting with the people there and the environment.

Omogho, E. M. (2021). Mother tongue disability and socio-cultural development in Nigeria. International Journal of Linguistics, Literature and Culture, 7(4), 255-262. https://doi.org/10.21744/ijllc.v7n4.1785 
- Mother tongue should be introduced in the school syllabus and taught in schools with more vigor and seriousness.

- The media should encourage the use of mother tongues by the public by incorporating them into some of their programs, for example, newscasting by television channels.

- The Nigerian government should be proactive in providing opportunities and privileges for children and youths who can speak and/or write and understand their mother tongues.

\section{Conflict of interest statement}

The author declared that (s)he has no competing interest.

Statement of authorship

The author has a responsibility for the conception and design of the study. The author has approved the final article.

Acknowledgments

I am grateful to two anonymous reviewers for their valuable comments on the earlier version of this paper. 


\section{References}

Aboiralor, K.C. (2008). Decline of mother tongue in Africa. Sunnewsonline.com Nigeria.

Adams, A \& Tulasiewics, W. (2005). What is mother tongue?. In Teaching in Multilingual Europe. New York: Continuum Publishers Co.

Adekunle, M. A (1960). Language in a multicultural context'. In E.N. Enenago (Ed.) Multilingualism minority languages and languages policy in Nigeria. Agbor: Central Books Limited.

Akindele, F. \& Adegbite, W, (1999). The Sociology and Politics of English in Nigeria: An introduction Ile-Ife, Nigeria: Obafemi Awolowo University Press Limited.

Awopetu, A. V. (2016). Impact of mother tongue on children's learning abilities in early childhood classroom. Procedia-Social and Behavioral Sciences, 233, 58-63. https://doi.org/10.1016/j.sbspro.2016.10.131

Babajide, A. O. (2001). Language Attitude Patterns of Nigerians: In Language Attitude and Language Conflict in West Africa. Igbo Anuse (Ed.) Ibadan: Enicronfit Publishers.

Bankole, A. (2012). Importance of mother tongue: In Tide News Online, Volume 8, August, 2012.

Cleo, A. (2001). Atlas linguistic. Ethnografico Da Regiao Sulddo Brasil 1\& 2 (2).

Cummins, J. (2001). Language, power and pedalogy. bilingual children in the Crossfier. New York: St. Matins Press.

Dingari, K. (2009). Importance of mother tongue for the immigrant children: In yahoo! Contributor Network, June 30.

Ezenwa-ohaeto, N. \& Akujobi, O.S. (2013). English as a second language in contemporary Nigerian Society: a reality or farce. Home> 4(1). Journalsenwaohaetorc.org.

Ferguson, A. (1968). Readings in the Sociology of Language. The Hague: Motion.

Fishmann, J. A., Ferguson, G.A. \& Gupata, J.D. (1968). Language Problem of Developing Nations. New York: John Wiley and Sons.

Giddens, A. (2009). Sociology. 6th edition. USA: Polity press Publishers.

Hammond, W.G. \& Scull Christine (2017). The J.R.R. Tolkien companion and guide (2 ${ }^{\text {nd }}$ ed.) London; Harper Collins.

Hicks, D. L., Santacreu-Vasut, E., \& Shoham, A. (2015). Does mother tongue make for women's work? Linguistics, household labor, and gender identity. Journal of Economic Behavior \& Organization, 110, 19-44. https://doi.org/10.1016/j.jebo.2014.11.010

Kochanska, G. \& Aksan, N.(1995). Mother-child mutually positive affect the quality of child compliance to requests and prohibitions, and maternal control as correlates of early internalization. Child Developments 66(1), 236-254. https://doi.org/10.2307/1131203.

Love, N., \& Ansaldo, U. (2010). The native speaker and the mother tongue. Language Sciences, 32(6), $589-593$. https://doi.org/10.1016/j.langsci.2010.09.003

Macaulay, M. (2004). 'Inadequate proficiency in English language and other Language-based in Nigeria Problems as Major Cause of the Spate of Juvenile Delinquency and Area Boys Syndrome in Nigeria: In V.T. Jike (Ed.) The Scourge of Child Labour in Nigeria: A Book of Readings. Lagos, Nigeria: Niss Publication. 164-170

Magwa, W. (2015). Attitudes towards the use of indigenous African languages as languages of instruction in education: A case of Zimbabwe. Journal of Educational Policy and Entrepreneurial Research, 2(1). www. Ilste.org.

Malv, H. (2004). About mother tongue. www.2-2.se/en/2.html

Moyo, T. (2001). The changing language policies and reversing language roles in Malawi from colonial times (1889 - 1964) to the present. Per Linguam, 17(2)1-11.

Murphy, L., \& de Larios, J. R. (2010). Searching for words: One strategic use of the mother tongue by advanced Spanish EFL writers. Journal of Second Language Writing, 19(2), 61-81. https://doi.org/10.1016/j.jslw.2010.02.001

Nondo, S.J. (1999). The main problems faced by students whose mother tongue are other Zimbabwe: unpublished..

Okafor, G. (2011). English as a second language in Nigeria. In a colloquiuim organized by Prof. Ezenwaohaeto, Resource centre, Awka.

Paker, T., \& Karaağaç, Ö. (2015). The use and functions of mother tongue in EFL classes. Procedia-Social and Behavioral Sciences, 199, 111-119. https://doi.org/10.1016/j.sbspro.2015.07.494

Rotimi, T. (2009). The functions of English in Nigeria from the earliest times to the present day. English Today. 25, 3-10. 1017/50266078409000121

Rotimi, T. (2012). The functioning of English in Nigeria from the earliest times to the present day. Journal of English Today, 25,3-10. Do-10.1017/50266078409000121.

Omogho, E. M. (2021). Mother tongue disability and socio-cultural development in Nigeria. International Journal of Linguistics, Literature and Culture, 7(4), 255-262. https://doi.org/10.21744/ijllc.v7n4.1785 
Roy, C. (1996). An interactional sociolinguistic analysis of turn-taking in an interpreted event. Interpreting, 1(1),3967.

Seid, Y. (2016). Does learning in mother tongue matter? Evidence from a natural experiment in Ethiopia. Economics of Education Review, 55, 21-38. https://doi.org/10.1016/j.econedurev.2016.08.006

Setati, M. (2013). Mathematics education and language diversity: A dialogue across settings. Journal for Research in Mathematics Education, 44(1), 119-128

Setati, M.(2005). Teaching Mathematics in a Primary multilingual classroom. Journal for Research in Mathematics Education, 36,447-460. Do-10.2307/30034945.

Vice web \& Kembo Sure (2000) African voices: an introduction to the languages and linguistics of Africa. African studies Review, 45 (3), 100.

Warren, D.K. (1904) Nonlinguistic cognitive performance and expressive languages cores in children with expressive language delay. MSC thesis. Online dissertations and thesis. Paper 4884. https//doi.org/10.15760/etd.6760

Web, V \& Sure, K. (2000). African voices: An introduction to the languages and linguistics of Africa, African studies Review, 45(3):100.

Wikipedia, the free encyclopedia (2008). First language wen.m.wikipedia.org $>$ wiki $>$ first language. 